\title{
Energy spectra of irregular surf waves
}

Fritz Büsching

Bielefeld : Univ. of Applied Sciences

Elektronisch veröffentlicht am 01.07.2014 in der Digitalen Bibliothek Braunschweig Publikationsserver des Wissenschaftsstandortes Braunschweig

unter: http://www.digibib.tu-bs.de/?docid=00056915

Elektronische Zweitveröffentlichung zu

Proc. 15th Int. Conf. on Coastal Engineering ICCE, Honolulu, USA, 1976, pp 539-559 
CHAPTER 31

ENERGY SPECTRA OF IRREGULAR SURF WAVES

by

Fritz BUSCHING ${ }^{1)}$

\section{ABSTRACT}

The investigations under consideration are based on synchronous measurements of waterlevel deflections $n(t)$ at some positions in a beach profile with a slope of approximately $1: 40$.

Surf conditions are studied during a severe storm surge as well as during periods of attenuating wave action.

By the use of a FOURIER ANALYZER 40 energy spectra are calculated which are also presented in integrated form (co-cumulative spectra). Because of different site arrangements it is possible to analyze the deformation of the spectra due to tide dependent changes of the water depth as wel1 as due to coastward decreasing water depth.

It happens that there are some phenomena associated with certain frequency bands.

With the water depth decreasing the energy densities in surf spectra are distributed over a wider frequency band.

In the present case unbroken waves are characterized by energy spectra in which at least $90 \%$ of the energy is represented by FOURIER components in the frequency range $0 \leq f \leq 0.5 \mathrm{~Hz}$. Increasing distribution of the energy densities over a wider frequency band represents at first breaking and finally broken waves. Sometimes the amount of energy coastward of the surf zone is higher than seaward of the breakers. This phenomenon can be explained by refraction effects caused by local nearshore bathymetry. A11 of there investigations were sponsored by the DEUTSCHE FORSCHUNGSGEMEINSCHAFT (German Research Foundation).

1) Dr.-Ing., Div. of Hydrodyn. and Coastal Engineering Techn. Univ. Braunschweig, Federal Republic Germany 


\section{INTRODUCTION}

As it is well known that the energy dissipation processes taking place in the surf zone cannot completely be simulated in a model (FOHRBOTER 1970 and 1971), since 1971 comprehensive field investigations have been performed on the west coast of the isle of SYLT/North Sea, see Fig. 1. FOHRBOTER (1974) investigated the behaviour of waves in the nearshore zone and inside the surf, presented first results on the influence of a longshore bar and on the energy decay perpendicular to the coast. Additionaly he proposed a $\beta$-number for a quantitative breaker classification.

DETTE (1974) reported on longshore currents in the range of high REYNOLDS-numbers and BOSCHING (1974) investigated the orbital velocities of irregular surf waves. Subject of the investigations under consideration are the changes in surf energy spectra due to tidal dependent and coastward decreasing water depth.

The intended structural analysis is based for the one thing on synchronous measurements of the waterlevel deflections $n(t)$, which were carried out during a heavy storm surge and for another on two measurements during attenuating weather conditions.

\section{MEASURING EQUIPMENT AND DATA ANALYSIS}

For the purpose of wave height measurements (water level deflections $n(t))$ pressure type wave meters working on inductive principle were attached to steel supports driven into the seabed at positions $85 \mathrm{~m}$, $100 \mathrm{~m}, 120 \mathrm{~m}$ and $128 \mathrm{~m}$ distant from the shoreline. Thus the deformation of the waves in a beach profile with a slope inclined 1:40 could be analyzed.

During the storm surge of December 13th to 14th 1973, only the devices at measuring positions $85 \mathrm{~m}$ and $100 \mathrm{~m}$ functioned satisfactorily, whereas during the later measurements also records from the two more offshore situated pressure devices at $120 \mathrm{~m}$ and $128 \mathrm{~m}$ could be received.

In order to analyze the data on a FOURIER ANALYZER all the measuring signals were fed to an analog magnetic tape recorder.

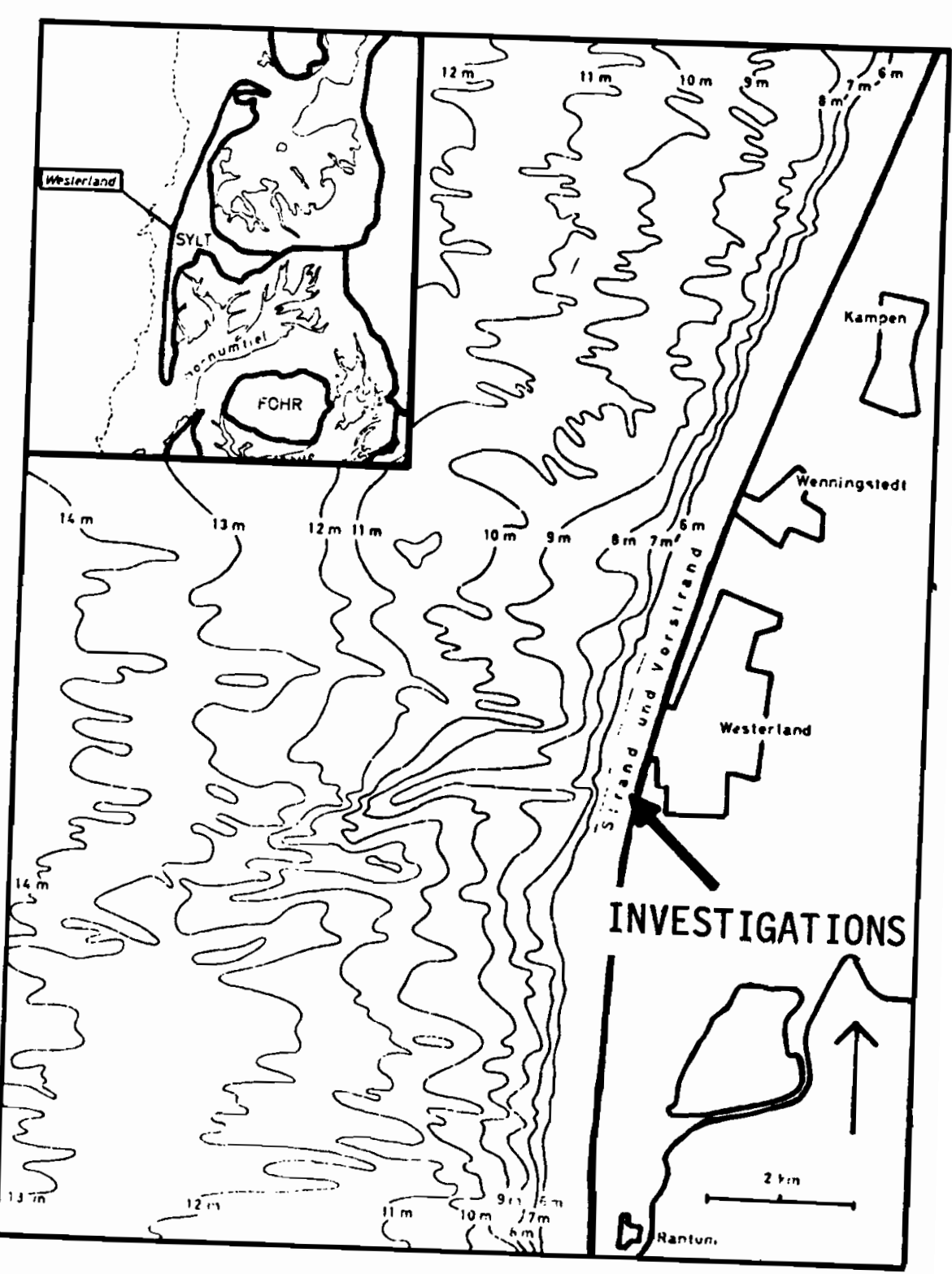

Fig. 1: Investigation area and underwater bathymetry west of the middle part of the isle of SYLT. Measured by surveying ships of DHI and WSA Kiel. After KOSTER (1974) 
The details of the measuring system are commented on by BOSCHING (1974) and FOHRBOTER and BUSCHING (1974).

Because of lack of space only a few things will be pointed out here:

1. For a wave analysis the maximum frequency $F_{\max }=F_{N}=\frac{1}{2 \Delta t}=3.125 \mathrm{~Hz}$

is relatively high.

2. The frequency resolution is characterized by $\Delta f=\frac{F_{\max }}{N / 2}=\frac{3.125}{256}=0.012207 \mathrm{~Hz}$ and

3. By averaging 10 successively calculated energy spectra, each representing $T_{R}^{\prime}=81.92 \mathrm{~s}$ measuring time, the resulting time of measurement was:

$T_{R}=10 \times 81.92=819.2 \mathrm{~s}$.

Comparing spectra calculated in the same manner one can expect to recognize the fundamental changes involved. This is why it seemed not to be necessary to deal with the method of calculation itself.

\section{ANALYZED MEASURING SERIES}

3.1. Storm Surge of December 13th to $14 \mathrm{th}, 1973$

The present storm surge data (water level deflections $n(t)$ ) had been previousiy analyzed by the author together with simultaneously recorded orbital velocity data.

Among others in that work an attachment of NORMAL IZED ENERGY SPECTRA and surf phenomena could be established.

Contrary to that the present evaluations deal with ABSOLUTE SPECTRA taken simultaneously at measuring positions $100 \mathrm{~m}$ and $85 \mathrm{~m}$.
During the storm surge period of about 30 hours at 16 measuring intervals samples were analyzed, see Fig. 2 and 3.

Each measuring interva 1 is represented by 4 diagrams consisting of the energy spectra at positions $100 \mathrm{~m}$ and $85 \mathrm{~m}$ with the respective cocumulative spectra beneath them.

In correspondence with wind and tidal dependant water level fluctuations peak energy densities $\left(E f_{p}\right)$ occured in the range of

$$
0.87 \mathrm{~m}^{2} / \mathrm{Hz} \leq E f_{p} \leq 4.38 \mathrm{~m}^{2} / \mathrm{Hz}
$$

\subsection{Simultaneous measurements of January 20th and 23 rd, 1974 respec-} tively

During the period of attenuating wave activity another two measurements have been carried out, each, however, consisting of 4 spectra, as to be seen from Fig. 4 and 5.

At the farther offshore positions (at $128 \mathrm{~m}$ and $120 \mathrm{~m}$ ) on January 20th a much wider peak due to higher wave activity at Bft. 6 can be seen than on January 23 rd at Bft. 3 only.

On the other hand both measurements show similar values of maximum energy density:

$$
E f_{p} \approx 1.1 \mathrm{~m}^{2} / \mathrm{Hz}
$$

In order to attach also these spectra to the respective wave deformation the synchronously recorded wave traces of two neighbouring devices have been shifted in such a way that there exists nearly no phase difference between them and thus changes could be recognized very well, see Fig. 6 and 7 . 

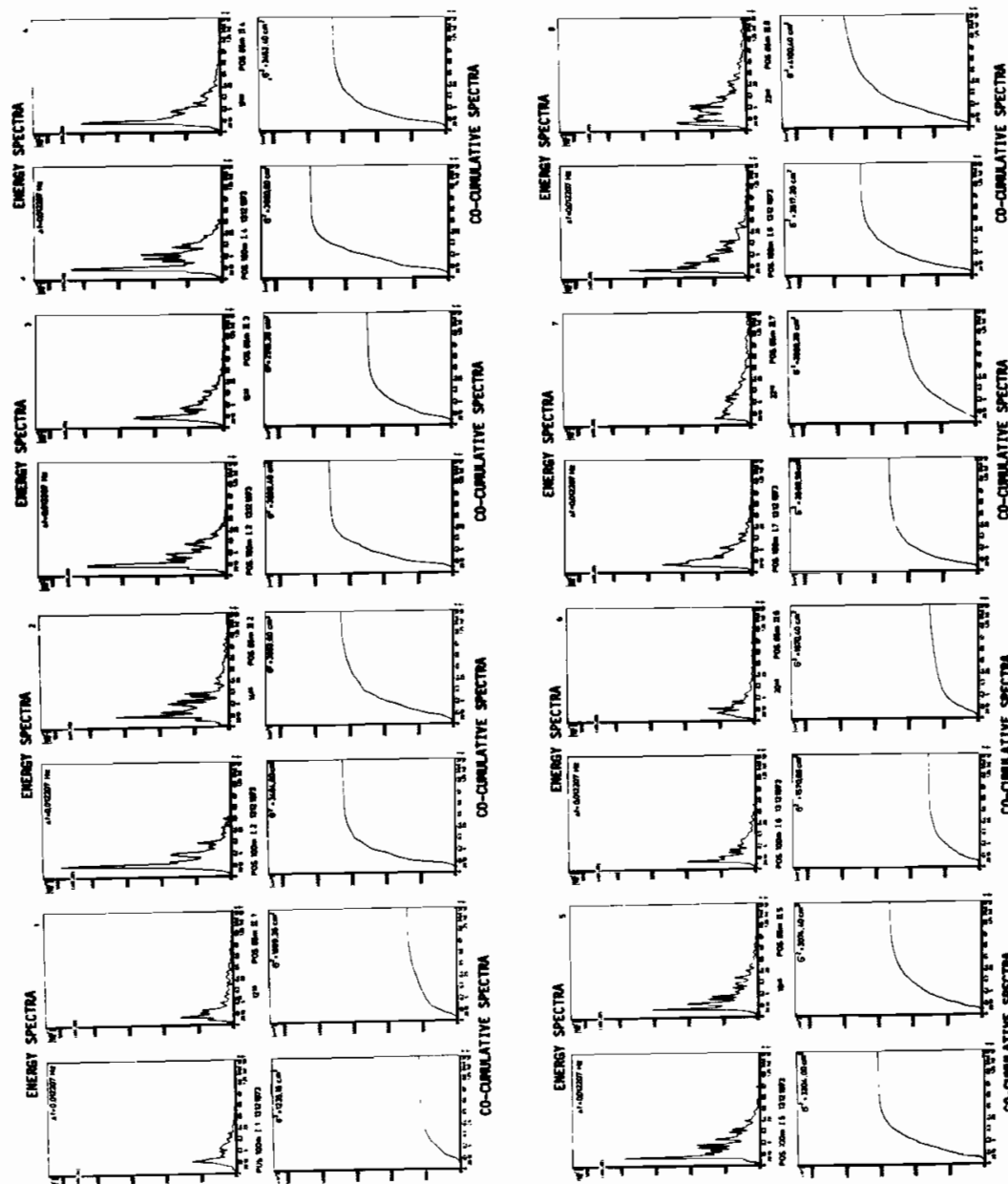

$\stackrel{2}{9}$

吾 萡 일

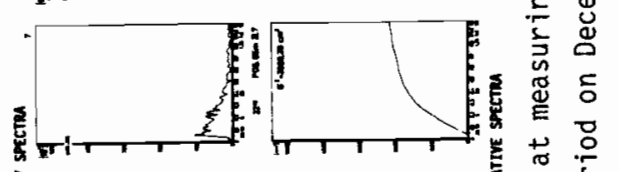

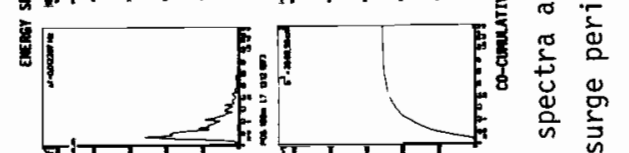

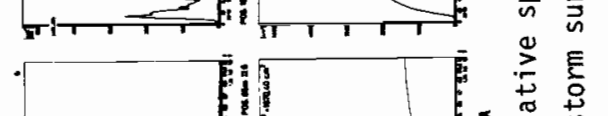

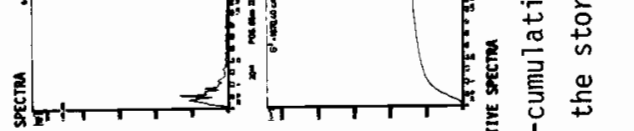
-

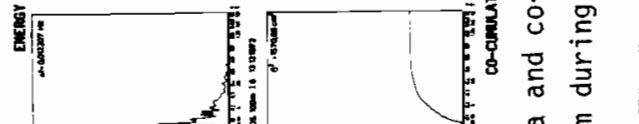

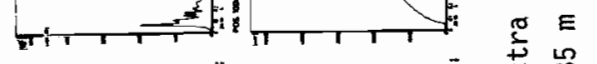
(1)

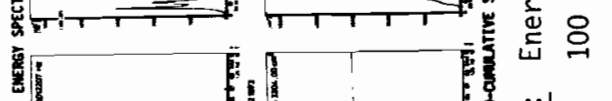

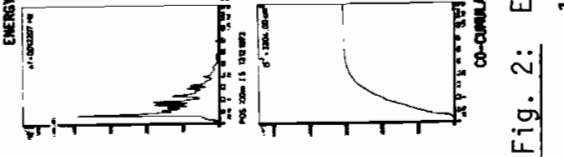

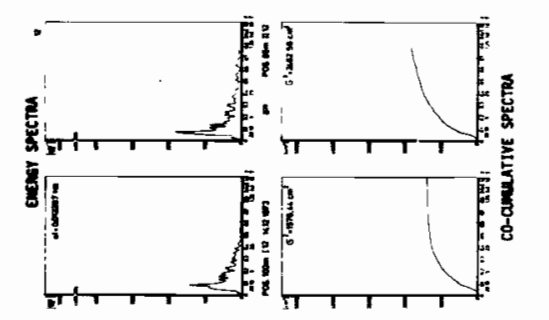

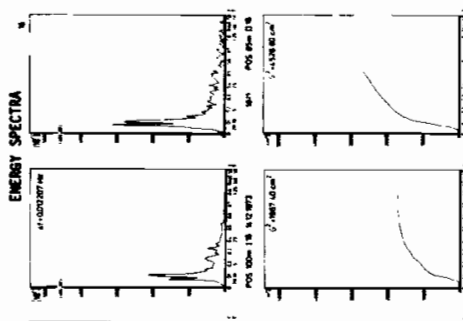

(5)
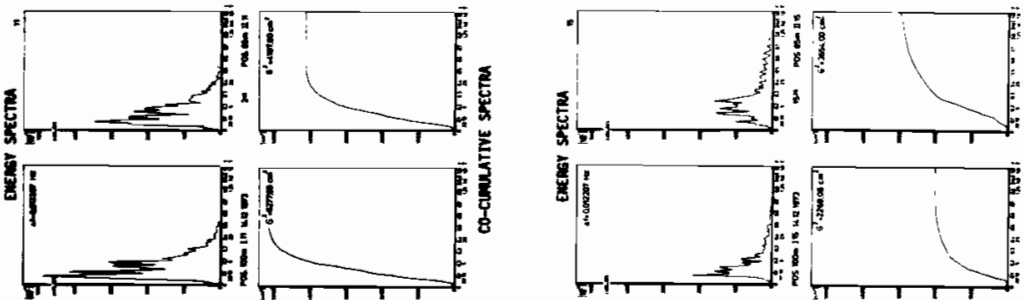

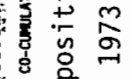
焉 要

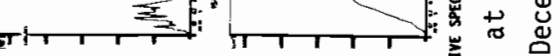
(1)

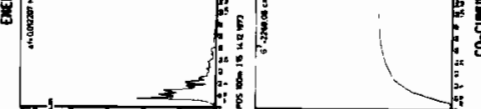

है
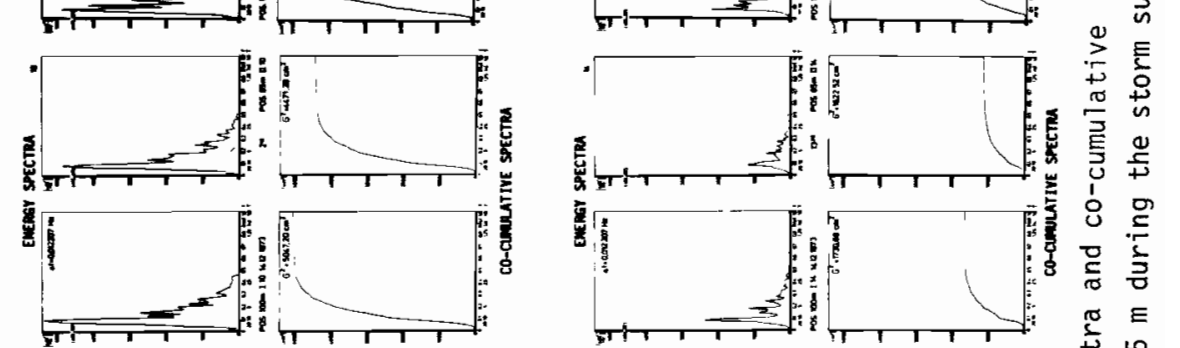

जे
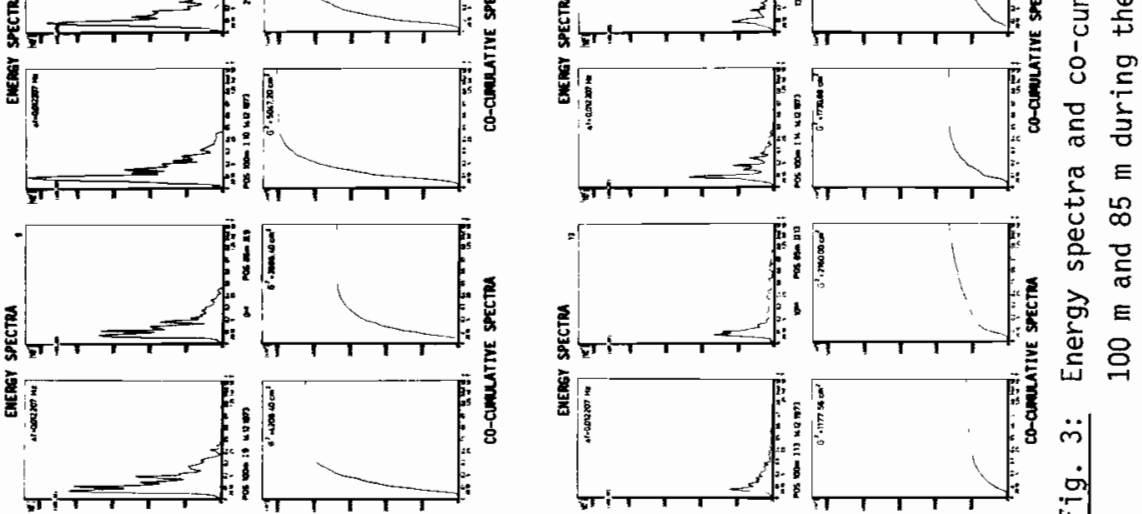

垔

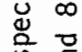

年

离

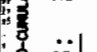

물 

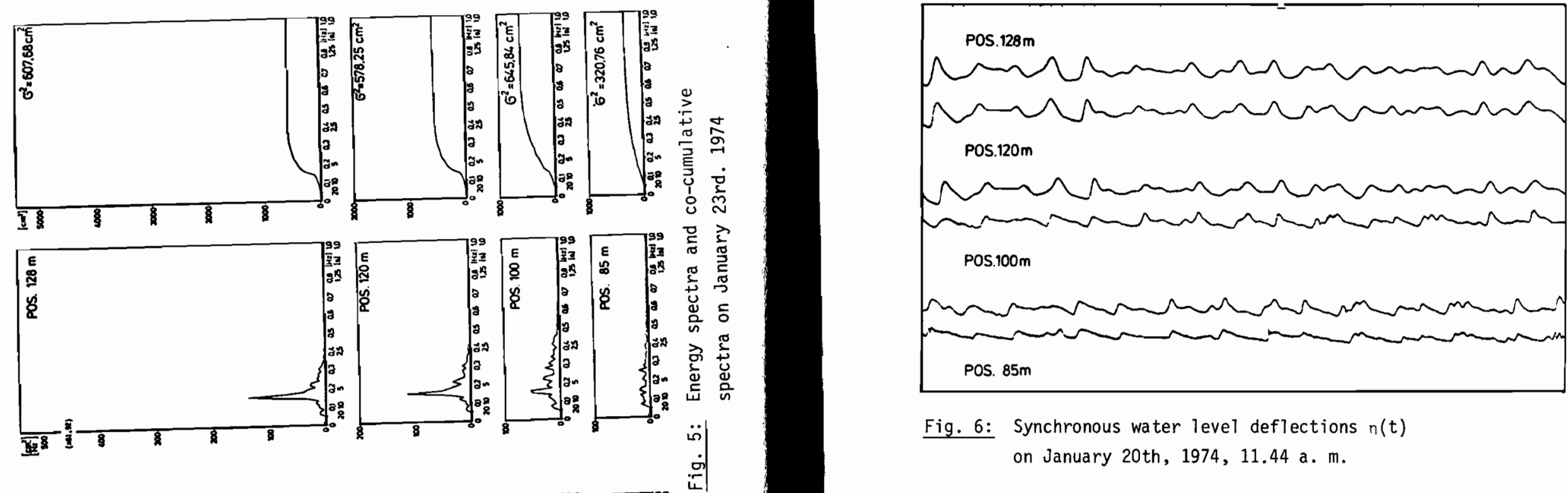

Fig. 6: Synchronous water level deflections $n(t)$ on January 20th, 1974, 11.44 a. m.
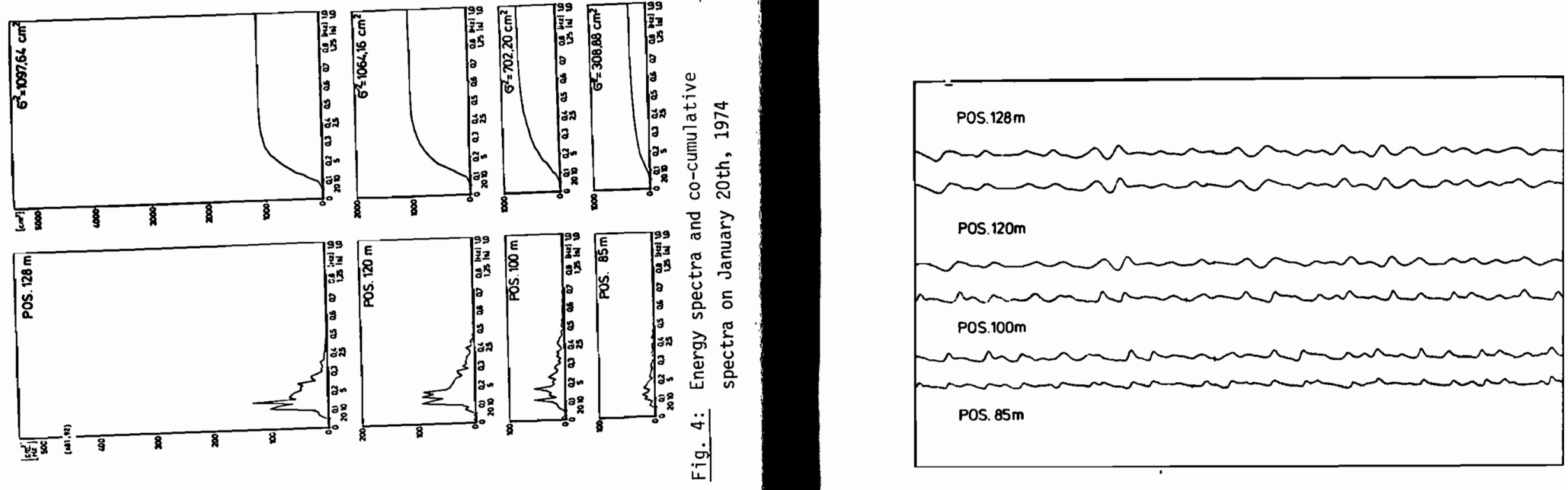

Fig. 7: Synchronous water level deflections $n(t)$ on January 23rd. 1974, 00.55 a. m. 
Comparing those two sets of strip charts the overall impression is that on January 20 th

the magnitude of water level deflections is somewhat higher,

the waves at position $128 \mathrm{~m}$ are steeper and

the perjods at position $85 \mathrm{~m}$ are much larger

As regards, however, the deformation and the stability of the waves in 列 ments:

particularly the traces at positions $128 \mathrm{~m}$ and $120 \mathrm{~m}$ are similar to a high degree; at Pos. $120 \mathrm{~m}$ they are only little steeper. At Position $100 \mathrm{~m}$ on an average nearly breaking waves are much steeper and at position $85 \mathrm{~m}$ less steepness indicates broken waves.

The problem of energy dissipation in limited water depth (in the ELBE estuary) was studied by SIEFERT (1974) using energy spectra. With regard to the structure of the spectra he agrees with the results of WALDEN and RUBACH (1967) and HASSELMANN and COLLINS (1968):

With the energy dissipation increasing the energy density decreases and the peak of energy density shifts to shorter periods (higher frequencies). For the swash zone SONU, PETTIGREW and FREDERICKS (1974) found the contrary to be true:

Energy spectrum variation in the upbeach direction reveals a low-pass filter effect of the beach along with an enhancement of energy density in an infragravity frequency band.

Regarding the appearances in nomal ised energy spectra of breakers, breaking and broken waves, from the auther's previous investigations the breaker zone turned out to be a transitional area:
With the water depth decreasing on the one hand the peaks of energy densities shift to lower frequency FOURIER components and at the same time some energy densities of a certain amount appear at higher frequencies.

In order to have a closer look into the processes taking place in the surf zone in the following the absolute spectra and co-cumulative spectra are analyzed, see Figures 2, 3, 4 and 5.

In the present study evaluations are carried out only to get a better interpretation of surf spectra; conclusions regarding the amount of energy dissipation are not drawn. In order to characterize the differences between the storm surge measurements and the remaining two measurements at attenuating wave action it shall only be mentioned here that the maximum peak energy density maxEf as well as the maximum variance $\max \sigma^{2}$

$$
\begin{aligned}
\max E f_{p} & =4.3817 \mathrm{~m}^{2} / \mathrm{Hz} \text { and } \\
\max \sigma^{2} & =0.5278 \mathrm{~m}^{2}
\end{aligned}
$$

both are a multiple of the respective measurements on January 20th and 23rd, 1974

Already from the graphs of the co-cumulative spectra (see Fig. 2 and 3) one can see that there is only a percentage of the total variance present in the frequency range in between 0 and $1 \mathrm{~Hz}$.

In this connexion total variances are denoted as the numerical values $\sigma^{2}$ calculated for the total analyzed frequency band and plotted into the upper part of the graphs.

The following 4 figures are prepa:ed for further illustration: In Fig. 8. the development of the variances $\sigma^{2}=f_{0}^{1} G n n(f) d f$ at the measuring positions $100 \mathrm{~m}$ and $85 \mathrm{~m}$ respectively are shown along with the tide curve of the investigation area. The characterizing changes shall be discussed describing the curves (1), (3) and (6). 


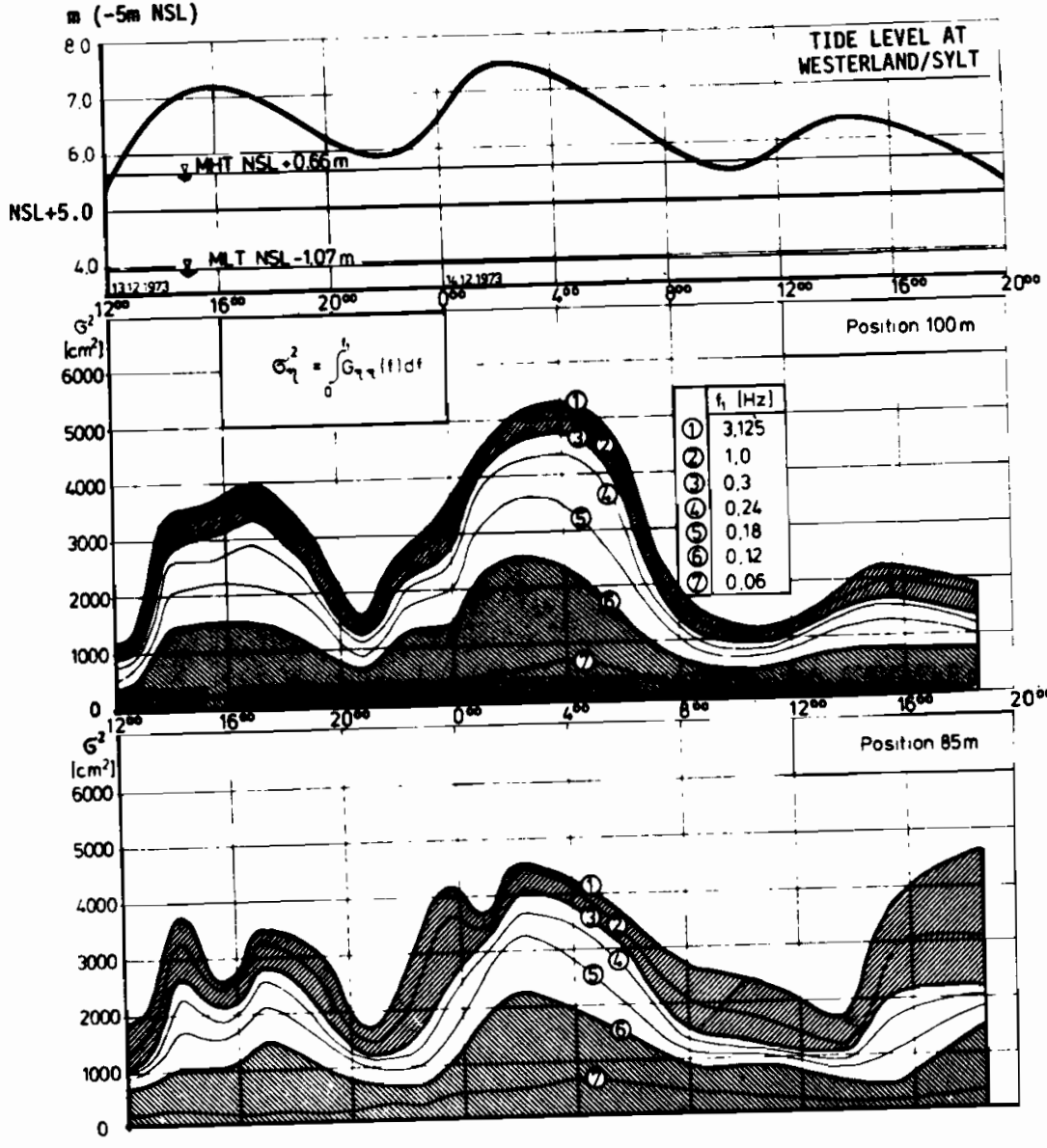

Fig. 8: Changes of the variance $\sigma^{2}$ during the storm surge measuring period of December 13 th to 14 th, 1973
A. Frequency range $0 \leq f \leq 3.125 \mathrm{~Hz}$ (Curve (1))

Apparently the coherence between wave energy and tide level at position $85 \mathrm{~m}$ is less than at position $100 \mathrm{~m}$ :

At $100 \mathrm{~m}$ distant from the shoreline high tide levels are in agreement with high wave energies whereas this is not true for the development of the variance at position $85 \mathrm{~m}$ where 5 maxima are to be recognized and the absolute maximum occurs at an extremely low water level at the end of the measuring period.

Comparing curves (1) at position $100 \mathrm{~m}$ and $85 \mathrm{~m}$ it is also obvious that sometimes the amount of energy nearer to the shore (i.e. at pos. $85 \mathrm{~m}$ ) is higher.

B. Curve (3) describes the variances of FOURIER components in between 0 and $0.3 \mathrm{~Hz}$

At position $100 \mathrm{~m}$ there is not a great difference to curve (1) but at position $85 \mathrm{~m}$ it is:

From the areas between curves (1) and (3) it can be stated that the increase of energy is predominantly due to high frequency FOURIER components at low water depth.

C. Also the amount of energy belonging to the longperiodic Fourier components ( $T>8 \mathrm{~s}$, curve (6)) shows good correlation to the water levels at position $100 \mathrm{~m}$. This is also true for the position $85 \mathrm{~m}$ until 8.00 a.m. on December 14 th 1973, but later on there are some changes to be recognized:

C.1 There is a minimum of energy coincident with the third high tide level and

C.2 just before and after this high tide level in this frequency range there are higher energies at position $85 \mathrm{~m}$ than at position $100 \mathrm{~m}$.

In Fig. 9 some percentages of the total variances (calculated for the frequency band $0 \leq f \leq 3.125 \mathrm{~Hz}$ ) are shown up to $1.0 \mathrm{~Hz}$. In order to 1 lustrate the fundamental changes involved there are 3 areas limited by the 50 - and 90 percentage variance isoline respectively. 


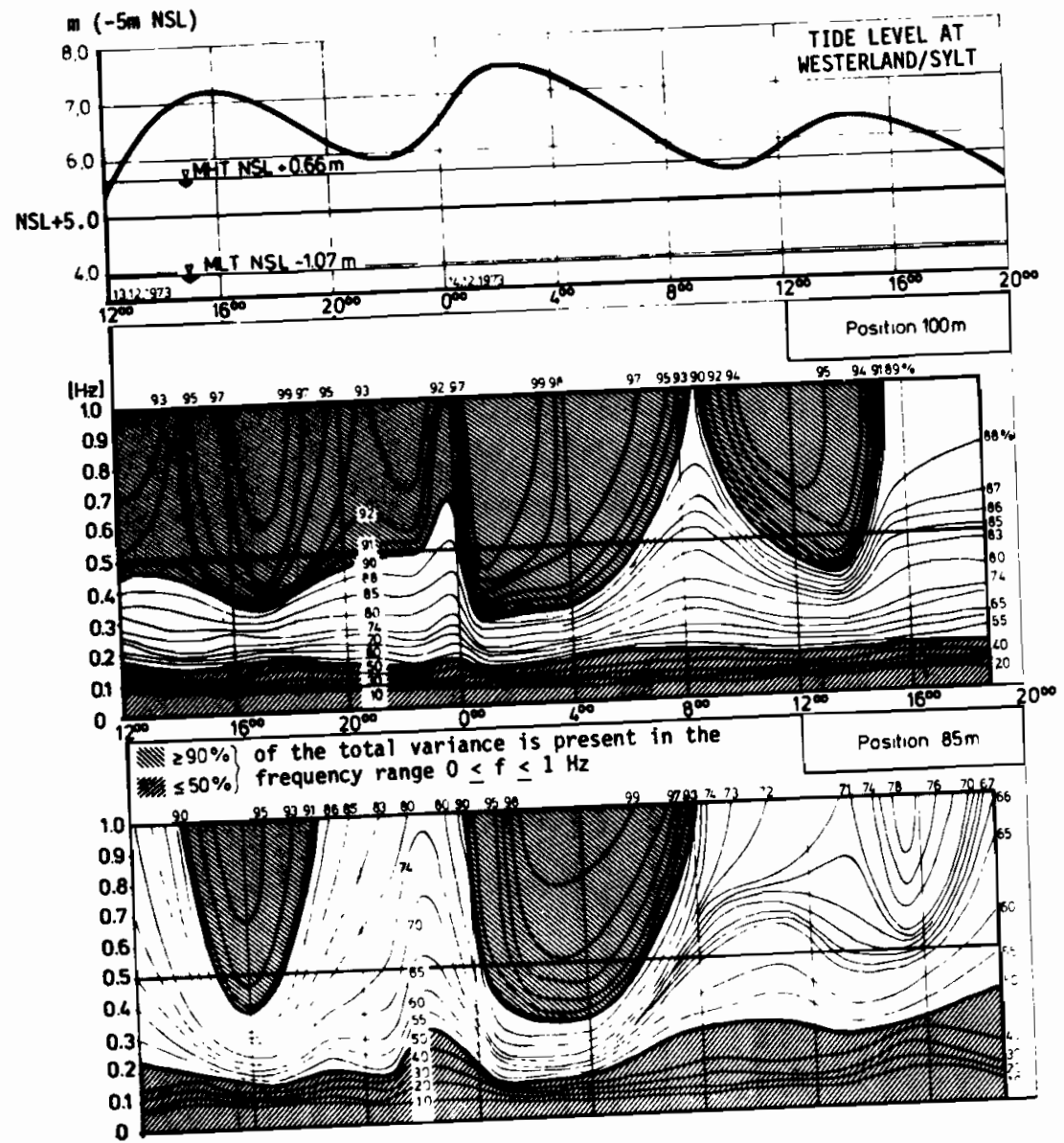

Fig. 9: Percentage variance isolines of the storm surge measuring period of December 13th to 14 th, 1973
At the measuring position $100 \mathrm{~m}$ from the coastline the relationship between tide level and certain percentage isolines is not quite clear:

The amount of $50 \%$ of the total energy seems to be constantly present at frequencies lower than $0.2 \mathrm{~Hz}$ whereas there is a fluctuation in the $90 \%$ isoline.

At position $85 \mathrm{~m}$, however, those two isolines show significant correlations to the tide levels: Exclusively at very high tide levels at least $90 \%$ of the total energy are present at frequencies between 0 and $0.5 \mathrm{~Hz}$, and in correspondence with low tide levels $50 \%$ of the total energy require a wider frequency band, i.e. frequencies up to $0.36 \mathrm{~Hz}$ maximum.

The evaluations of the synchronous measurements of 4 pressure devices on January 20 th and 23 rd have been carried out in a similar manner. Contrary, however, to the plots of the storm surge data in Figures 10 and 11 the changes are shown as functions of the shoreline distance.

During the measurements on January 20th at position $128 \mathrm{~m}$ nearly the total energy (more then $99 \%$ of $\sigma^{2}=1097.64 \mathrm{~cm}^{2}$ ) is present in the frequency range $0 \leq f \leq 0.5 \mathrm{~Hz}$. With the waves approaching the shore the energy continousiy decreases.

On January 23rd the energy at the farthest offshore position is only about half as much but similar to the above mentioned appearences there is an increase of energy nearer to the shore (at pos. $100 \mathrm{~m}$ ).

\section{CONCLUSIONS:}

In consideration of the surf phenomena detected from strip chart records of the storm surge measurements (see BOSCHING 1974) in generell it can be stated that at low tide levels the energy present in surf spectra is distributed over a wider frequency band. This statement is in accordance with

a) the results of a theoretical investigation on the deformation of sinusoidal waves increasingly deformed (steepened) by 


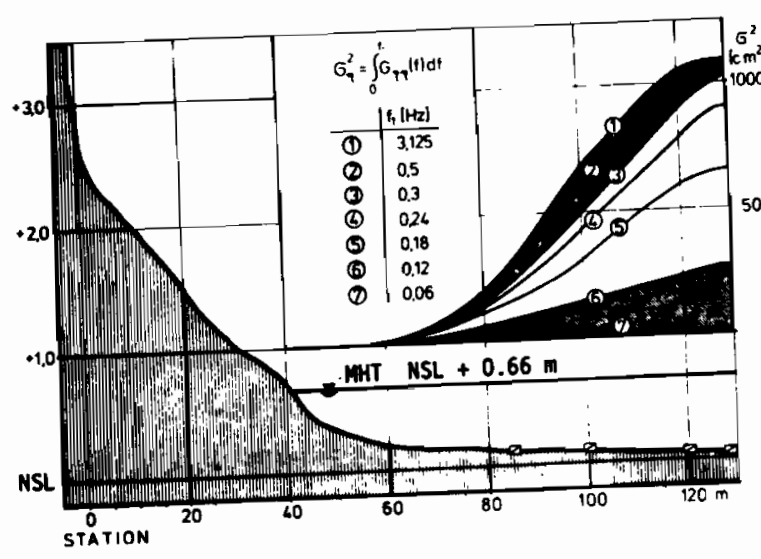

Fig. 10: Coast normal wave energy decrease on January 20th, 1974, $11.44 \mathrm{a} . \mathrm{m}$.

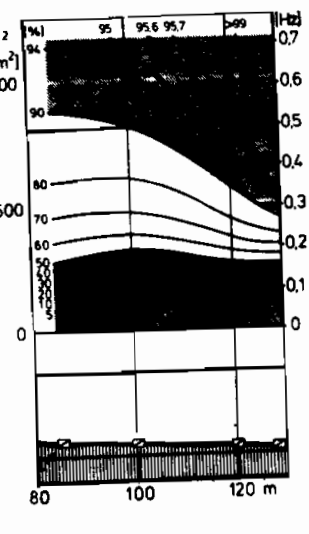

Percentages of the energy present in the frequency range $0 \leq f \leq 0.78 \mathrm{~Hz}$

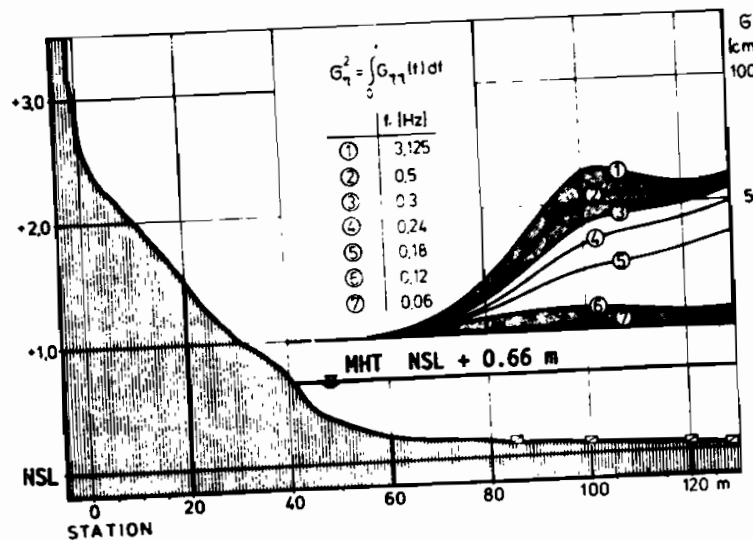

Fig. 11: Coast normal wave energy decrease on January 23rd, 1974, 00.55 a.m.

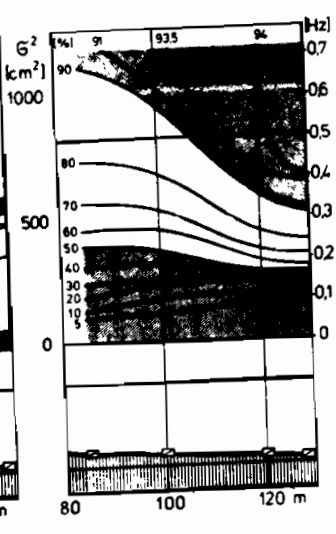

Percentages of the energy present in the frequency range $0 \leq f \leq 0.78 \mathrm{~Hz}$ decreasing water depth. SCHULEJKIN (1956) found out that the energy associated with higher harmonics increases at the expense of the fundamental oscillation.

b) The decomposition of original waves into two or more waves (solitons) reported from wave tank investigations by GALVIN (1972).

Comparing surf energy spectra and respective strip chart records of the storm surge measurements for the present case it can be stated that unbroken waves are characterized by spectra in which at least $90 \%$ of the energy is represented by FOURIER components in between 0 and $0.5 \mathrm{~Hz}$. Increasing destribution of energy densities over a wider frequency band at first stands for breaking and finally signifies broken waves.

The statement is in accordance with the measurement on January 20th, $197 \mathrm{~A}$ (see Fig. 10) but for the measurement on January 23 rd it demands for the instability of the waves to have occured seaward of position $100 \mathrm{~m}$ (see Fig. 11). Thus it can be concluded that the interpretation of the wave deformation (see Fig. 7) has to be changed in such a way that the wave trace at position $100 \mathrm{~m}$ already represents breaking waves - probabely spilling breakers.

As far as the energy increase in upbeach direction is concerned, it is obvious that this increase is due to Fourier components of frequencies higher than $0.3 \mathrm{~Hz}$ emerging at relatively low water levels. On the other hand at minimum water depth (before and after the last high tide of the storm surge measurement) there is another energy increase in the frequency range $0 \leq f \leq 0.12 \mathrm{~Hz}$ (curve (6), Fig. 8).

Apparently this is in accordance with the shifting of peak energy densities to lower frequencies in line with coastward or tidal dependent water level decrease (see SONU et al 1974 and BOSCHING 1974). 
In the following an explanation of the temporary energy increase in the upbeach direction is presented. Fig. 1 shows the investigation area on the isle of Sylt with a bar located offshore perpendicular to the coast. Although this bar is relatively far away from the beach it can not be excluded that some phenomena result from it even on the beach:

The higher energies may be explained by refraction effects (interference) in such a manner that breaking waves are focussed on a special point in the measuring profile. The position of this point, i.e. the distance from the shoreline depends an the water depth present. This explanation is in agreement with visual observations. Frequently wave systems of little differing directions of propagation could be watched thus producing cross surf. Accordingly on January 23rd a focal point must have been near position $100 \mathrm{~m}$ whereas on January 20 th at a higher tide level broken waves collided coastward of position $85 \mathrm{~m}$ and therefore could not be registered by the pressure devices.

As concerns the intensity of the interfering waves another conclusion can be drawn from the above mentioned previous study:

In Fig. 12 the resulting wave directions calculated from orbital velocity components (via transfer functions) are shown for the storm surge measurements on December 13 th and 14 th at position $85 \mathrm{~m}$ together with a levelling curve also describing the changes of the wind directions. In the study under consideration (BOSCHING 1974) an explanation of the deviations from the mean line could not yet be given.

If, however, those deviations are compared with the fluctuation of wave energy present at position $85 \mathrm{~m}$ (see Fig. 8) a rather good correlation turns out until December $14 \mathrm{th}, 8.00 \mathrm{a} . \mathrm{m}$.

As this agreement also would be significant after $8.00 \mathrm{a} . \mathrm{m}$, if the amount of energy due to long periodic wave run up (just before and after the last high tide level) would not be considered, it might be concluded that the indicated variations of velocity directions result from the differing intensities of the contributing wave systems caused by refraction.

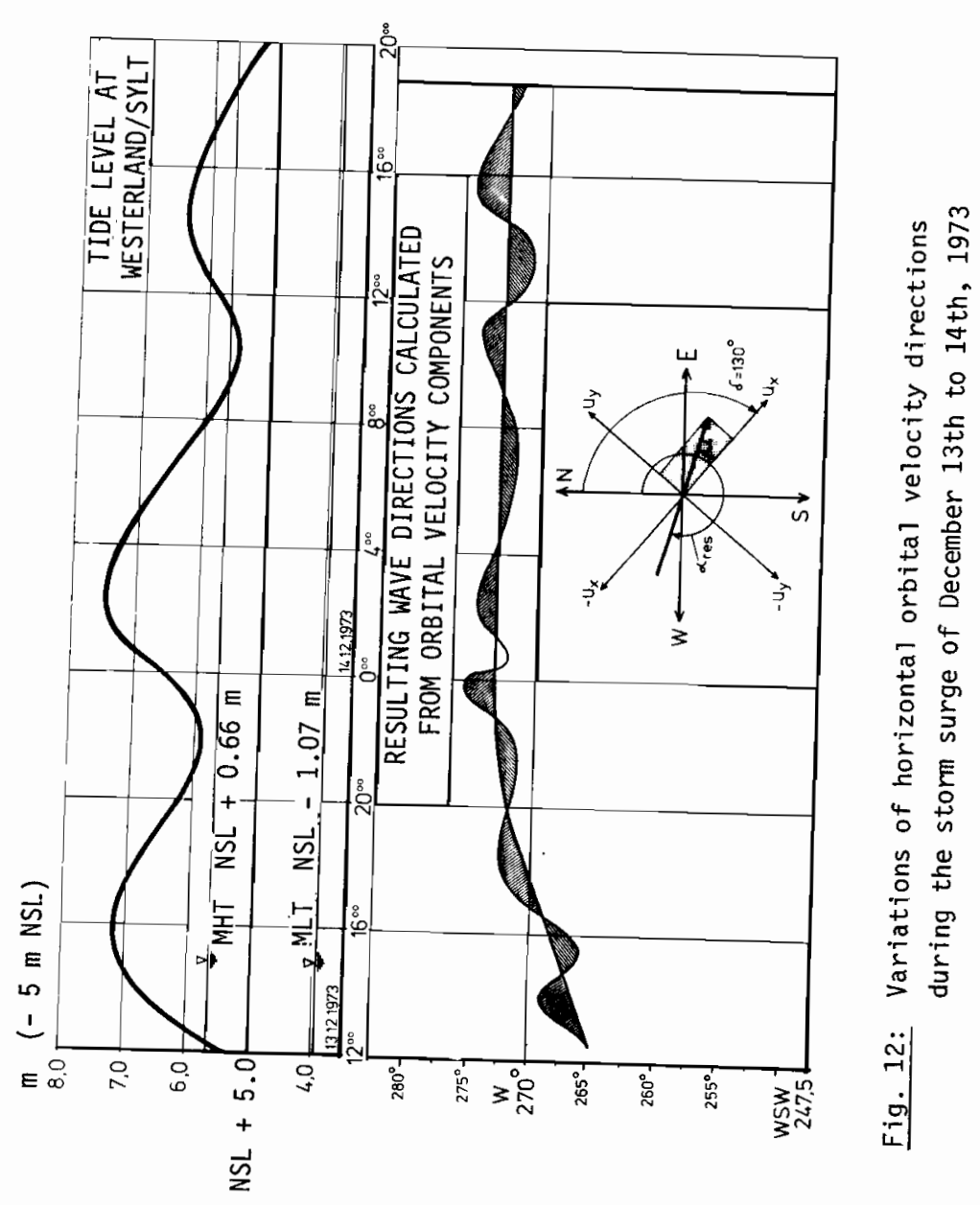




\section{REFERENCES}

BUSCHING, $F$. 1974

BOSCHING, F. 1975

DETTE, H. H. 1974

FOHRBOTER, A. 1970

FOHRBOTER, A. 1971

FÜRBOTER, A. 1974

FOHRBOTER, A. BUSCHING, $F$. 1974
Ober Orbitalgeschwindigkeiten irregulärer Brandungswel len Mitt. LEICHTWEISS-INSTITUT der Technischen Universität Braunschweig, Heft 42, 1974

Ober die Änderungen von Wellenperioden im Brandungsbereich Mitt. LEICHTWEISS-INSTITUT der Technischen Universität Braunschweig, Heft 47, 1975

Ober Brandungsströmungen im Bereich hoher REYNOLDS-Zahl en Mitt. LEICHTWEISS-INSTITUT der Technischen Universität Braunschweig, Heft 41, 1974

Air Entrainment and Energy Dissipation in Breakers

Proc. XIIth Coastal Engineering Conference Washington, 1970

Ober die Bedeutung des Lufteinschlages für die Energieumwandlung in Brecherzonen

a) Mitt. Franzius-Institut

Technische Universität Hannover, Heft 36, 197

b) Die Kuiste, Heft 21, 1971

Einige Ergebnisse aus Naturuntersuchungen in Brandungszonen

Mitt. LEICHTWEISS-INSTITUT der Technischen

Universität Braunschweig, Heft 40, 1974

Wave Measuring Instrumentation for Field Invest gations on Breakers

OCEAN WAVE MEASURING AND ANALYSIS, Volume 1 , New Orleans; USA 1974, Published by ASCE New Yo
GALVIN, C.J.Jr. 1972

HASSELMANN, $\mathrm{K}$.

COLLINS, J.I.

1968

KOSTER, R.

1974

SCHULEJKIN, W. W.

1960

SIEFERT, W.

1974

SONU, C. J.

PETTIGREW, N. und FREDERICKS, R. G. 1974

WALDEN, $\mathrm{H}$. RUBACH, H.J. 1967
Wave Breaking in Shallow Water in "Waves on Beaches", edited by R. E. Meyer, Acedemic Press,

Inc. New York and London, 1972

Spectral Dissipation of Finitedepth Gravity Waves Due to Turbulent Bottom Friction Journal of Mar., Res. Vol. 26, №. 1, 1968

Geologie des Seegrundes vor den Nordfriesischen Insein Sylt und Amrum

MEYNIANA 24, S. 27 - 41, Kie1, 1974

Theorie der Meereswellen

Akademie-Verlag Berlin 1960

Ober den Seegang in Flachwassergebieten Mitt. LEICHTWEISS-INSTITUT der Technischen Universität Braunschweig, Heft 40, 1974

Measurement of Swash Profile and Orbital Motion on the Beach

Proc. International Symp. OCEAN WAVE MEASUREMENT AND ANALYSIS

Sept. 9 - 11, 1974, New Orleans, Lousiana, USA, 1974

Gleichzeitige Messungen mit nichtstabilisierten Beschleunigungsschreibern an Orten mit unterschiedlicher Wassertiefe in der Deutschen Bucht Dt. Hydrogr.Zeitschrift, Bd. 20, Heft 4, 1967 